\title{
Characterization of a Dominant Electron Trap in GaNAs Using Deep-Level Transient Spectroscopy
}

Conference Paper NREL/CP-520-38334

August 2006

S.W. Johnston, S.R. Kurtz, and R.S. Crandall

Presented at the 2005 MRS Fall Meeting Boston, Massachusetts

November 28 - December 2, 2005
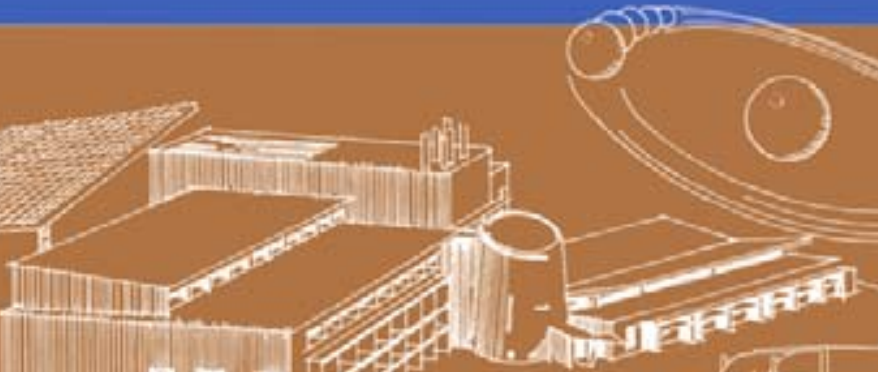


\section{NOTICE}

The submitted manuscript has been offered by an employee of the Midwest Research Institute (MRI), a contractor of the US Government under Contract No. DE-AC36-99G010337. Accordingly, the US Government and MRI retain a nonexclusive royalty-free license to publish or reproduce the published form of this contribution, or allow others to do so, for US Government purposes.

This report was prepared as an account of work sponsored by an agency of the United States government. Neither the United States government nor any agency thereof, nor any of their employees, makes any warranty, express or implied, or assumes any legal liability or responsibility for the accuracy, completeness, or usefulness of any information, apparatus, product, or process disclosed, or represents that its use would not infringe privately owned rights. Reference herein to any specific commercial product, process, or service by trade name, trademark, manufacturer, or otherwise does not necessarily constitute or imply its endorsement, recommendation, or favoring by the United States government or any agency thereof. The views and opinions of authors expressed herein do not necessarily state or reflect those of the United States government or any agency thereof.

Available electronically at http://www.osti.gov/bridge

Available for a processing fee to U.S. Department of Energy and its contractors, in paper, from:

U.S. Department of Energy

Office of Scientific and Technical Information

P.O. Box 62

Oak Ridge, TN 37831-0062

phone: 865.576 .8401

fax: 865.576 .5728

email: mailto:reports@adonis.osti.gov

Available for sale to the public, in paper, from:

U.S. Department of Commerce

National Technical Information Service

5285 Port Royal Road

Springfield, VA 22161

phone: 800.553 .6847

fax: 703.605.6900

email: orders@ntis.fedworld.gov

online ordering: http://www.ntis.gov/ordering.htm 


\title{
Characterization of a Dominant Electron Trap in GaNAs Using Deep-Level Transient Spectroscopy
}

Steven W. Johnston, Sarah R. Kurtz, and Richard S. Crandall

National Renewable Energy Laboratory, Golden, CO 80401, U.S.A.

\begin{abstract}
Dilute-nitrogen GaNAs epitaxial layers grown by metal-organic chemical vapor deposition were characterized by deep-level transient spectroscopy (DLTS). For all samples, the dominant DLTS signal corresponds to an electron trap having an activation energy of about 0.25 to 0.35 $\mathrm{eV}$. The minority-carrier trap density in the p-type material is quantified based on computer simulation of the devices. The simulations show that only about $2 \%$ of the traps in the depleted layer are filled during the transient. The fraction of the traps that are filled depends strongly on the depth of the trap, but only weakly on the doping of the layers and on the conduction-band offset. The simulations provide a pathway to obtain semi-quantitative data for analysis of minority-carrier traps by DLTS.
\end{abstract}

\section{INTRODUCTION}

Deep-level transient spectroscopy (DLTS) [1] studies of GaNAs have reported several levels of both hole and electron traps [2-6]. We reported diodes exhibiting only one dominant electron trap peak in both Zn-doped, p-type and Se-doped, n-type GaNAs. The appearance of these DLTS peaks with added $\mathrm{N}$ correlated to a detrimental reduction in the solar cell's open-circuit voltage beyond that associated with decreased bandgap $[7,8]$.

In this paper, we explore this DLTS data in more detail. We use modeling to quantify the fraction of the depletion width that is affected by the DLTS-measurement applied biases and then calculate the trap density accordingly. We assess the sensitivity of this modeling to a number of parameters, thus developing the tools to quantify DLTS studies of minority-carrier traps.

\section{EXPERIMENTAL DETAILS}

The epitaxial layers studied here were grown by atmospheric-pressure metal-organic chemical vapor deposition using triethylgallium, arsine, and dimethylhydrazine on $\mathrm{p}$ - and n-type conductive GaAs substrates. The growth temperature was $650^{\circ} \mathrm{C}$. Samples were grown with increasing amounts of $\mathrm{N}$ for both $\mathrm{p}$-type and $\mathrm{n}$-type GaNAs [7]. The samples were intentionally doped: $\mathrm{p}$-type using $\mathrm{Zn}$ with room temperature values near $8 \times 10^{16} \mathrm{~cm}^{-3}$, and $\mathrm{n}$-type using $\mathrm{Se}$ with room temperature values near $7 \times 10^{17} \mathrm{~cm}^{-3}$. The bandgaps ranged from 1.4 to about $1.2 \mathrm{eV}$. A pn junction was formed by depositing a more-heavily doped $\left(2 \times 10^{18} \mathrm{~cm}^{-3}\right)$ n-type or p-type GaAs layer on the p-type or n-type GaNAs, respectively. Finally, 1- $\mathrm{mm}^{2}$ ohmic contacts were deposited on top.

Capacitance-voltage (CV) and DLTS data were collected using an Accent Optical Technologies Fourier transform DLTS system [9]. This system uses a 1-MHz modulating signal. Samples were measured between $0 \mathrm{~V}$ and $1 \mathrm{~V}$ reverse bias. The leads connected to the sample contacts were reversed to apply opposite polarity bias to n-type samples. Traps were filled when the sample, which was held at a reverse bias of $1 \mathrm{~V}$, was biased to $0 \mathrm{~V}$ for $1 \mathrm{~s}$. 


\section{RESULTS AND DISCUSSION}

The DLTS data for the N-varying samples are shown in Figure 1. The addition of small amounts of $\mathrm{N}$ led to peaks in the DLTS spectra for both p-type and n-type GaNAs. As shown in the left graph of Figure 1, a positive peak corresponding to minority-carrier electron trapping occurs near $125 \mathrm{~K}$ using a $23 \mathrm{~s}^{-1}$ rate window for the p-type GaNAs samples. The middle graph of Figure 1 shows a negative peak, corresponding to a majority-carrier electron trap, occurring between $150 \mathrm{~K}$ and $170 \mathrm{~K}$ for the n-type GaNAs samples. For all samples, the long filling pulse of $1 \mathrm{~s}$ allowed the DLTS signal to reach saturation in magnitude [10]. The peak heights, which are roughly proportional to trap density, increase with increasing $\mathrm{N}$ content. The right graph of Figure 1 shows DLTS data for all recorded rate windows summarized in the form of an Arrhenius plot [11]. The linear fits of these data are used to calculate the trap activation energies and capture cross-sections [11]. The p-type samples vary in $\mathrm{N}$ content from $0.02 \%$ to $1.2 \%$. Their electron trap activation energies are $0.27 \pm 0.03 \mathrm{eV}$, and their cross sections range from $2 \times 10^{-15}$ to $4 \times 10^{-13} \mathrm{~cm}^{2}$. The n-type samples vary in $\mathrm{N}$ content from $0.011 \%$ to $0.45 \%$. Their electron trap activation energies are $0.35 \pm 0.03 \mathrm{eV}$, and their cross sections range from $2 \times 10^{-13}$ to $1 \times 10^{-12} \mathrm{~cm}^{2}$.

The left graph of Figure 2 shows $\mathrm{CV}$ data for a representative p-type sample. The inset shows temperature-dependent $-1 \mathrm{~V}$-bias capacitance values. The right graph of Figure 2 shows that the p-type samples' net hole concentrations determined from CV measurement [11] decreased by factors of 2 to 3 as temperature decreased from about $400 \mathrm{~K}$ to lower temperatures. The linear fits illustrate the uniform doping density over the bias range used for the DLTS measurement.

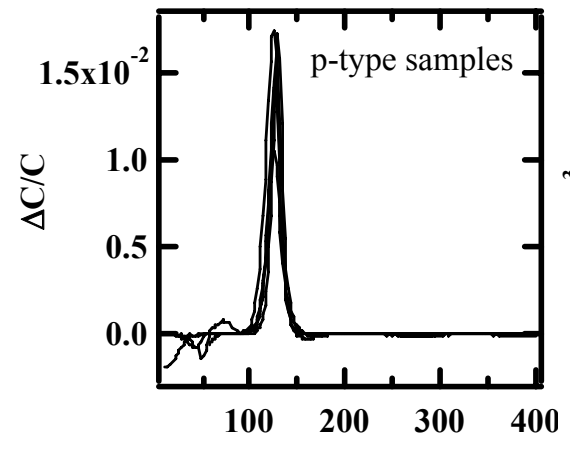

Temperature (K)
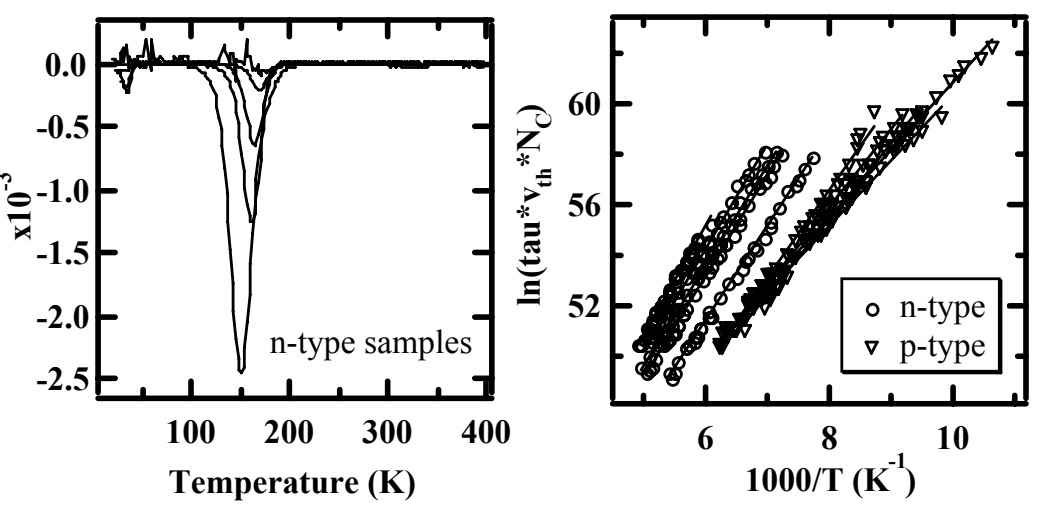

Figure 1. The left and middle graphs show DLTS data $\left(23 \mathrm{~s}^{-1}\right.$ rate window and $1 \mathrm{~s}$ filling time) for the p-type and n-type GaNAs samples, respectively. The right graph shows the Arrhenius plot created from DLTS data. Circles correspond to majority-carrier electron traps in n-type material, and triangles correspond to minority-carrier electron traps in p-type material. 

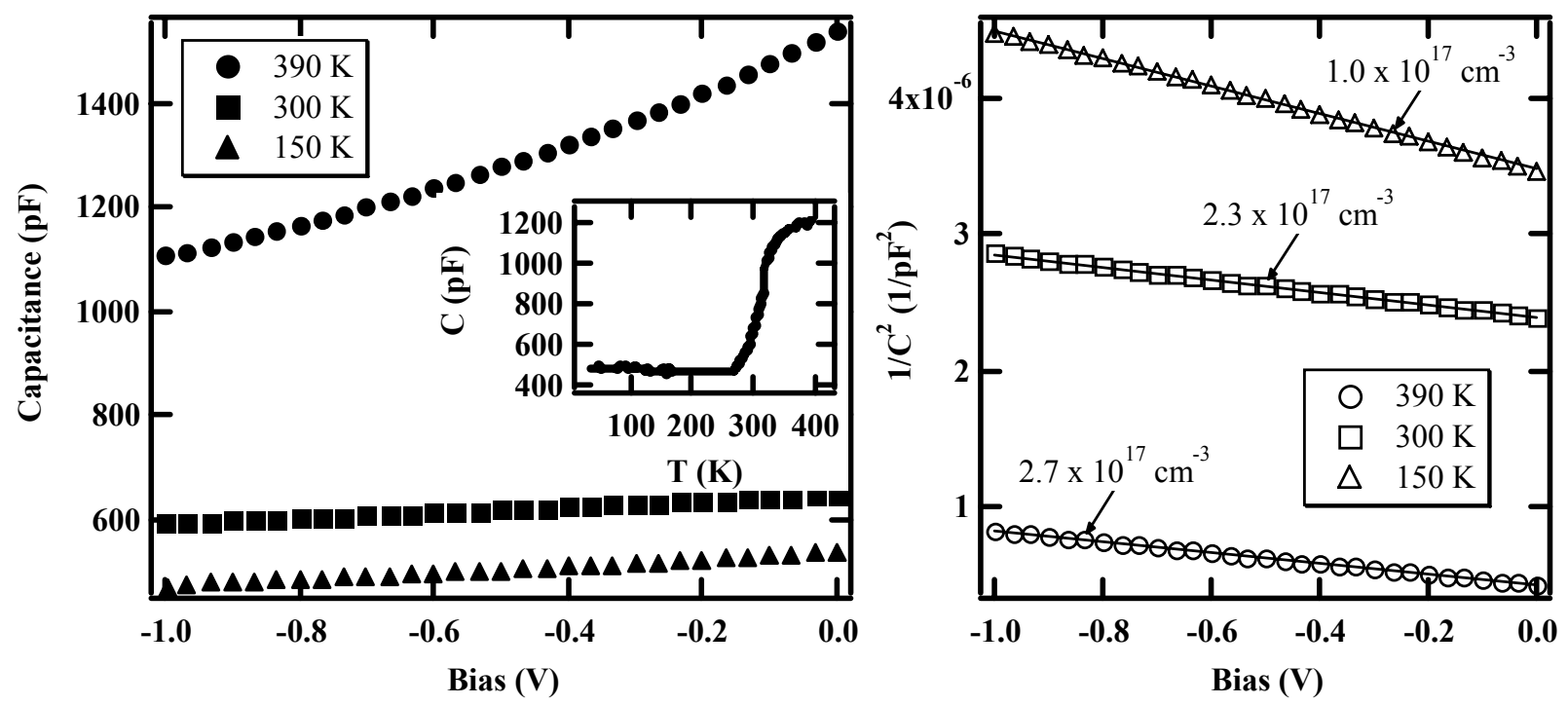

Figure 2. Capacitance-voltage data taken at various temperatures for a p-type GaNAs sample. The left graph shows CV at 390,300, and $150 \mathrm{~K}$, and the inset shows capacitance at -1V as a function of temperature. The right graph shows the Mott-Schottky plot with linear fits giving carrier concentrations at 390,300 , and $150 \mathrm{~K}$.

The CV data for the n-type samples [10] (not shown) also have good linear fits, representative of uniform doping over the measurement region. Unlike the p-type samples, the n-type samples' net electron concentrations decreased by less than $10 \%$ when cooling from high to low temperature.

Detecting minority-carrier traps without the use of forward bias or light is not a typical result; however, we have consistently observed electron traps in p-type GaNAs samples. We have previously described how experimental values of trap filling time and applied-bias-dependent depth profiling agree with modeling that the electrons fill and emit from trap states near the interface between n-type GaAs (or metal for a Schottky-barrier sample) and p-type GaNAs [12]. In this paper, we use modeling to calculate a correction factor for determining the electron trap density.

Each p-type sample is modeled at DLTS-peak temperatures $(\sim 140 \mathrm{~K})$ using simulation software. The conduction and valence bands and quasi-Fermi levels are determined for $0 \mathrm{~V}$ and $1 \mathrm{~V}$ reverse-bias conditions. A trap level with the Arrhenius-plot-derived activation energy is included, and the occupation of this trap is calculated based on the electron quasi-Fermi level. The graphs of Figure 3 show the modeled band diagrams for a $2 \times 10^{18} \mathrm{~cm}^{-3} \mathrm{n}$-type GaAs layer on a $1 \times 10^{17} \mathrm{~cm}^{-3}$ p-type GaNAs layer, where the interface is at $0.10 \mu \mathrm{m}$. Band bending in the depletion region causes the trap level to cross the electron quasi-Fermi level near the metallurgical pn junction $(\sim 0.11 \mu \mathrm{m})$. At $-1 \mathrm{~V}$, electron traps nearer the junction from the crossing point always remain filled. Then, at $0 \mathrm{~V}$, the band bending is slightly lowered such that the crossing point moves slightly farther from the junction. This leaves empty traps below the electron quasi-Fermi, which electrons from the n-type side can fill by surmounting the potential energy due to the band bending in the depletion region $[10,12]$. According to a thermionic emission estimate [13], the time to fill these traps at low temperature where the DLTS peak 

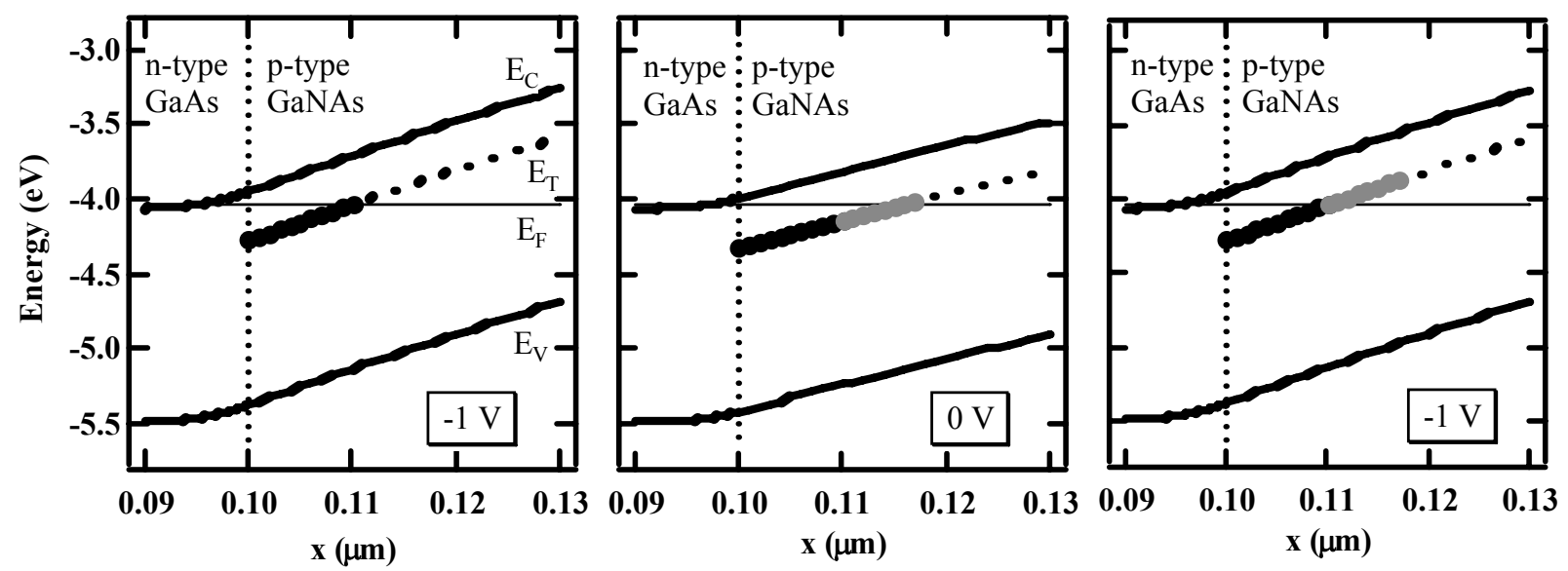

Figure 3. The left, center, and right graphs show the band diagrams for conditions before, during, and immediately after trap filling, respectively. Traps that remain filled are highlighted in black. Traps that fill and emit with changing bias conditions are highlighted in gray.

occurs agrees with the experimental values of approximately $1 \mathrm{~s}$ observed for the p-type samples $[10,12]$. After the filling pulse, the bias is returned to $-1 \mathrm{~V}$, and now these filled traps are above the electron quasi-Fermi level such that they will emit with times characteristic of the trap activation energy and sample temperature and be observed by the DLTS capacitance transient.

The trap density, $\mathrm{N}_{\mathrm{T}}$, is initially calculated based on room-temperature carrier concentration and the simplified equation [11],

$$
N_{T, D L T S} \approx 2 N_{a} \frac{\Delta C}{C},
$$

where $\mathrm{N}_{\mathrm{a}}$ is net acceptor concentration, $\Delta \mathrm{C}$ is the DLTS change in capacitance, and $\mathrm{C}$ is the reverse-bias capacitance. Equation 1 assumes the trap density is small compared to doping and that traps are filled throughout the total depletion width. The total charge due to filling and emptying traps is then given by

$$
Q=N_{T, D L T S} x_{d},
$$

where $x_{d}$ is the depletion width. From the modeled results, though, we can determine the region where traps are actually filling and emitting as shown in Figure 3. The trapped charge is the difference between the zero bias and $1-\mathrm{V}$ reverse bias conditions given by

$$
Q=\left.\int_{0}^{x_{0}} N_{T, a c t u a l} f\left(E_{T}\right)\right|_{0 V} d x-\left.\int_{0}^{x_{0}} N_{T, a c t u a l} f\left(E_{T}\right)\right|_{-1 V} d x
$$

where $f\left(E_{T}\right)$ is the Fermi-Dirac distribution function that gives the probability that the electron trap energy state at $E_{T}$ will be occupied by an electron. Finally, the actual trap density is given as a function of the simplified trap density by equating total charge: 


$$
N_{T, \text { actual }}=N_{T, D L T S} \frac{x_{d}}{\left.\int_{0}^{x_{d}} f\left(E_{T}\right)\right|_{0 V} d x-\left.\int_{0}^{x_{0}} f\left(E_{T}\right)\right|_{-1 V} d x} .
$$

This resulting factor increases the p-type samples' trap densities by up to 40 to 60 times. For ptype samples, these trap densities range from $1 \times 10^{17}$ to $4 \times 10^{17} \mathrm{~cm}^{-3}$ for low to high $\mathrm{N}$ content.

The trap density adjustment modeling in p-type samples is most sensitive to the values of activation energy used. Variations of up to $0.1 \mathrm{eV}$, affected possibly by high-field Poole-Frenkel emission $[10,14]$, may change the adjustment factors by up to $30 \%$. This, along with other uncertainty analysis calculations, is shown in Figure 4. The baseline model consisted of a $2 \times 10^{18}$ $\mathrm{cm}^{-3}$ n-type GaAs layer on a $1 \times 10^{17} \mathrm{~cm}^{-3}$ p-type GaNAs layer at $140 \mathrm{~K}$, which described a representative p-type sample. A grid of 10 points per $1 \mathrm{~nm}$ was used in the simulation. The measured trap activation energy was $0.32 \mathrm{eV}$, and the left graph of Figure 4 shows how the trap density correction factor is modified if only this value is changed. Other perturbations modeled include simulation temperature, GaAs n-type doping, GaNAs p-type doping, and GaNAs bandgap. These are shown in the graphs of Figure 4, but have less effect on the correction factor than the trap activation energy. Finally, other factors, such as uncertainties in the DLTS peak fitting and $\mathrm{CV}$ data fitting to get carrier concentration, contribute by adding about $10 \%$ error.

Electrons fill traps in n-type material as majority carriers. Trap densities are also adjusted to account for the region, which is smaller than the total depletion region, where electron traps fill and emit according to the bias conditions [11]. This calculation results in a factor of 4 increase for the n-type samples' trap density over that calculated by Equation 1 when biases of -1V and $0 \mathrm{~V}$ are used in the DLTS measurement. For n-type samples, the corrected trap densities range from $8 \times 10^{14}$ to $4 \times 10^{16} \mathrm{~cm}^{-3}$ for low to high $\mathrm{N}$ content.

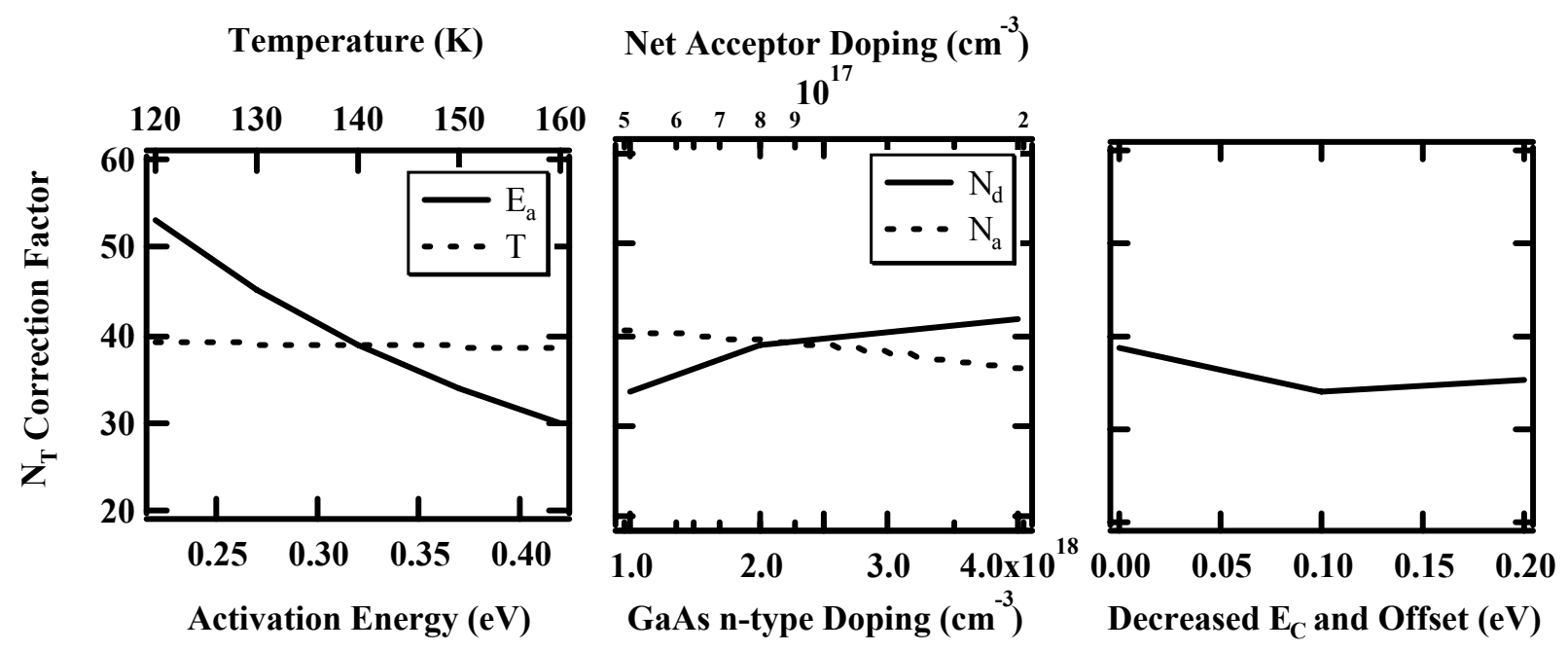

Figure 4. The left graph shows the trap density correction factor as a function of trap activation energy and simulation temperature. The middle graph shows the trap density correction factor as a function of net n-type GaAs doping level and net p-type GaNAs doping level. The right graph shows the trap density correction factor as a function of GaNAs bandgap, with all of the offset at the interface in the conduction band. 


\section{SUMMARY}

An electron trap dominated the DLTS spectra for both p-type and n-type GaNAs samples. In p-type GaNAs, the electron trap had a measured activation energy of about 0.25 to $0.3 \mathrm{eV}$. In ntype GaNAs, the activation energy was about $0.35 \mathrm{eV}$. Trap density adjustment factors were calculated for both p-type and n-type samples. In n-type samples, the majority-carrier trap concentrations were increased by about a factor of 4 , whereas in p-type samples, the minoritycarrier traps (which are usually not reported for pn junctions in reverse bias) showed very large correction factors of 40 to 50 . Thus, we have used modeling to quantify the trap densities of minority-carrier electron traps in p-type GaNAs.

\section{REFERENCES}

1. D. V. Lang, J. Appl. Phys. 45, 3023 (1974).

2. K. M. Chen, Y. Q. Jia, Y. Chen, A. P. Li, S. X. Jin, and H. F. Liu, J. Appl. Phys. 78, 4261 (1995).

3. D. Kwon, R. J. Kaplar, and S. A. Ringel, Appl. Phys. Lett. 74, 2830 (1999).

4. P. Krispin, S. G. Spruytte, J. S. Harris, and K. H. Ploog, J. Appl. Phys. 89, 6294 (2001).

5. P. Krispin, S. G. Spruytte, J. S. Harris, and K. H. Ploog, Appl. Phys. Lett. 80, 2120 (2002).

6. R. J. Kaplar, D. Kwon, S. A. Ringel, A. A. Allerman, S. R. Kurtz, E. D. Jones, and R. M. Sieg, Sol. Energy Mater. Sol. Cells 69, 85 (2001).

7. S. Kurtz, S. W. Johnston, J. F. Geisz, D. J. Friedman, and A. J. Ptak, Thirty-First IEEE PVSC, 595 (2005).

8. S. Kurtz, S. Johnston, and H. M. Branz, Appl. Phys. Lett. 86, 113506 (2005).

9. S. Weiss and R. Kassing, Solid-State Electron. 31, 1733 (1988).

10. S. W. Johnston and S. R. Kurtz, unpublished.

11. P. Blood and J. W. Orton, The Electrical Characterization of Semiconductors: Majority Carriers and Electron States (Academic, San Diego, 1992).

12. S. W. Johnston, S. R. Kurtz, D. J. Friedman, A. J. Ptak, R. K. Ahrenkiel, and R. S. Crandall, Appl. Phys. Lett. 86, 072109 (2005).

13. S. M. Sze, Physics of Semiconductor Devices, $2^{\text {nd }}$ ed. (Wiley, New York, 1981).

14. P. A. Martin, B. G. Streetman, and K. Hess, J. Appl. Phys. 52, 7409 (1981). 


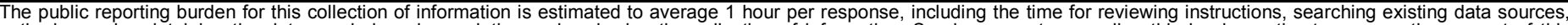

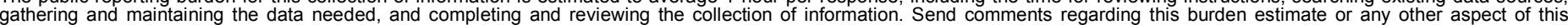

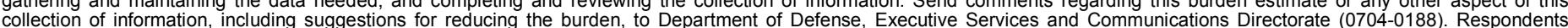

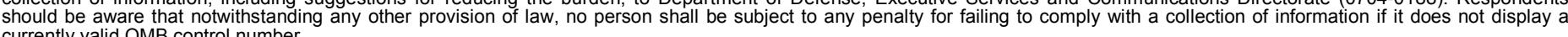

PLEASE DO NOT RETURN YOUR FORM TO THE ABOVE ORGANIZATION.

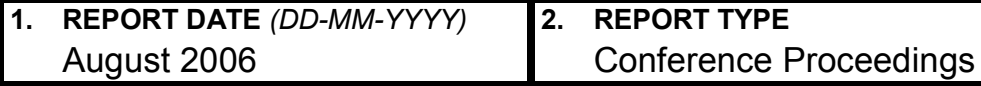

4. TITLE AND SUBTITLE

Characterization of a Dominant Electron Trap in GaNAs Using

Deep-Level Transient Spectroscopy
3. DATES COVERED (From - To)

5a. CONTRACT NUMBER

DE-AC36-99-GO10337

5b. GRANT NUMBER

5c. PROGRAM ELEMENT NUMBER

5d. PROJECT NUMBER

NREL/CP-520-38334

5e. TASK NUMBER

PVA63101

5f. WORK UNIT NUMBER
7. PERFORMING ORGANIZATION NAME(S) AND ADDRESS(ES)

National Renewable Energy Laboratory

1617 Cole Blvd.

Golden, CO 80401-3393
8. PERFORMING ORGANIZATION REPORT NUMBER

NREL/CP-520-38334

9. SPONSORING/MONITORING AGENCY NAME(S) AND ADDRESS(ES)

10. SPONSOR/MONITOR'S ACRONYM(S) NREL

11. SPONSORING/MONITORING AGENCY REPORT NUMBER

12. DISTRIBUTION AVAILABILITY STATEMENT

National Technical Information Service

U.S. Department of Commerce

5285 Port Royal Road

Springfield, VA 22161

13. SUPPLEMENTARY NOTES

14. ABSTRACT (Maximum 200 Words)

Dilute-nitrogen GaNAs epitaxial layers grown by metal-organic chemical vapor deposition were characterized by deep-level transient spectroscopy (DLTS). For all samples, the dominant DLTS signal corresponds to an electron trap having an activation energy of about 0.25 to $0.35 \mathrm{eV}$. The minority-carrier trap density in the p-type material is quantified based on computer simulation of the devices. The simulations show that only about $2 \%$ of the traps in the depleted layer are filled during the transient. The fraction of the traps that are filled depends strongly on the depth of the trap, but only weakly on the doping of the layers and on the conduction-band offset. The simulations provide a pathway to obtain semi-quantitative data for analysis of minority-carrier traps by DLTS.

15. SUBJECT TERMS

PV; deep-level transient spectroscopy; metal-organic; chemical vapor deposition; minority carrier; devices.

\begin{tabular}{|c|c|c|c|c|c|}
\hline \multicolumn{3}{|c|}{ 16. SECURITY CLASSIFICATION OF: } & \multirow{3}{*}{$\begin{array}{l}\text { 17. LIMITATION } \\
\text { OF ABSTRACT } \\
\text { UL }\end{array}$} & \multirow{3}{*}{$\begin{array}{l}\text { 18. NUMBER } \\
\text { OF PAGES }\end{array}$} & \multirow[t]{2}{*}{ 19a. NAME OF RESPONSIBLE PERSON } \\
\hline \multirow{2}{*}{$\begin{array}{l}\text { a. REPORT } \\
\text { Unclassified }\end{array}$} & \multirow{2}{*}{$\begin{array}{l}\text { b. ABSTRACT } \\
\text { Unclassified }\end{array}$} & \multirow{2}{*}{$\begin{array}{l}\text { c. THIS PAGE } \\
\text { Unclassified }\end{array}$} & & & \\
\hline & & & & & 19b. TELEPHONE NUMBER (Include area code) \\
\hline
\end{tabular}

